\title{
How to Select An Online Program
}

\author{
Allan Beck, University of Texas Pan American, USA
}

\begin{abstract}
It seems that prospective students, in pursuit of tools that make them good candidates for advancement in their current professions, are looking at online learning opportunities and a viable and acceptable option to traditional onground education. Colleges, universities and other teaching outlets are recognizing the problems with committed, busy working adults, and they are offering alternative venues by which students can earn credit and ultimately, a degree. Many students come to these classes unprepared for what lies ahead. This paper will address the shortcomings, and recommend avenues to success.
\end{abstract}

Keywords: Online education, Internet-based learning, online program selection, Cyber learning, alternative learning programs.

\section{INTRODUCTION}

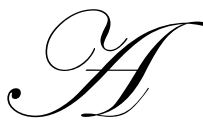

s simple as the topic may seem, many students pursuing a degree via the online medium come into it assuming and unprepared for the journey which lies ahead. They are often under the assumption that the classes are self-paced and they are not adequately ready to take on the rigors which an online program may offer.

The first thing that students need to become versed in is the format and the platform from which they will learn. Is this an environment that they are familiar with? Is this a platform that they need to understand better or receive additional training before they just decide to enroll in a program? It should be an environment that they can be familiar and comfortable operating in for the life of the program. For many online degrees, this can take several years.

Another thing that is very important when considering an online education is whether to select a synchronous or asynchronous program. This choice may be important, given your ability to attend a class at the same time each week depending on how the class is structured. One should further consider other important aspects, such as your learning style and your self-discipline when it comes to motivating yourself to attend and to keep up with the work, Individuals will not have the pressure and support that an on-ground class offers. Whatever is a best fit is the way to go, as "results have shown no significant differences in achievement by format" (Roblyer, Freeman, Donaldson \& Maddox, 2007).

Some individuals may view one as more advantageous than the other. Asynchronous classes are useful in "cultivating thoughtful interaction and allows students to react and respond," but synchronous classes happen in real time and are spontaneous in nature. Problems may include the "lack of reflection time" and getting all students together at once (Johnson, 2006).

Further, many programs rely heavily on the concept of team projects. If you work well while collaborating with others, this may be for you. If however, you do better, and feel better about being graded solely on your own independent effort, this environment may not be right for you.

Many online programs offer a sample class, or better yet, a mini-class whereby you can - usually at no cost attend an abbreviated class and see if the platform and the learning environment are right for you. These are especially important in the selection of a school and a program and should not be overlooked. Don't get started on a 
program that will only frustrate you and perhaps discourage you to the point of dropping out. Remember your goal and the motivation that sent you looking for the right program. Make sure that it is a good fit for you as you want to successfully complete what you set out to achieve.

Many feel that the online route is going to be easier than on-ground education, but this simply isn't true. The content is essentially the same, the assignments are not any less, but the difference that is you can attend during a day and time of your choice (Consider this when Choosing a Graduate Program, 2005). Typically, classes, terms or semesters are much shorter, yet more concentrated online than on-ground. You usually take a single, much focused class each time, rather than perhaps many classes in an on-ground offering. Of course, as a nigh student in a traditional on-ground setting, you may be taking only a single class; but for a regular degree-seeking student, this isn't the case. An online class usually makes for a more compact timeframe in which to complete assignments. It may also require a minimum number of online postings and require you to be online a number of days during every week. Make sure that you have the time and can meet this commitment. In most cases, online education requires a strict attendance component that cannot be overridden by the instructor. It is automatically tracked by the number of times that you log in or by the number of postings that you make as your contribution to the class discussions.

Even though one may lose the benefit of body language when attending a class online, one may be surprised by the frank and forthright dialog that takes place in the virtual environment. There is definitely less intimidation attending class from the confines of your home, the library, or perhaps even while dining out. Online students often have to be reminded to treat others with respect, as this 'no intimidation' environment can get personal and people will defend their point of view in earnest. The upside to this is that many of the classes in a virtual classroom consist of dispersed students with a variety of experiences. It is this diversity that truly enhances the quality of discussions much more than a homogeneous on-ground class consisting of like students with like backgrounds. In a previous study, over $50 \%$ of the participants indicated that "anonymity improved honesty during forum dialogs" (Bertera \& Littlefield, 2003).

The fact that many prospective candidates may have careers that make them mobile, whether it is weekly, monthly, or even every few years, may make it impossible to start and finish a degree program in a single on-ground institution. This is a major decision point when considering the option of enhancing your credentials or putting you in a better position for promotion when considering your career from a long-term point of view.

Typically, many online students are ones that may have been away from school for quite some time. This isn't always the case, but it is for a portion of the online population. These people may be older than traditional students and they may be more intimidated by the use of technology in the deliverance of their education. For this student component, it is important to feel comfortable with the support staff and tools which the school may offer. This is something that should be thoroughly discussed with a school counselor or advisor. Don't be intimidated by the advisor that is aggressively trying to grow the school population by smoothing over answers and leaving you with more questions. If your questions are not fully answered to your satisfaction, then you should not proceed. You need to feel comfortable before making a commitment. This is not only a commitment of time; it is one of other resources as well. Some other factors to consider when selecting a program or institution for the adult learner include "factors that contribute to the facilitation of online learning include effective course design, understanding the technologies, developing one's own online style, the multiple roles of the facilitator and effective group interaction" (Merrill, 2003). There are many different variables that promote the complexity of your decision.

Some online candidates may have strong family commitments and not be able to attend class at any given time or day. The online educational choice may be right for this student. Especially in an asynchronous environment, one can attend class even after putting the children to bed and after the rest of the family has settled in for the night. Likewise, a person that works an off-shift may have difficulty staying awake during another time of day, and the online option allows them to go to class whenever it is most convenient to them.

The prospective student should also do their homework on accreditation. There are many organizations offering degrees and many that offer degrees without ever having to attend class. Remember to fully investigate the merit of a program before you ever commit money to a program. Know the cost and the benefits before you begin. 
Cost of the program may vary from one institution to another, and you should make sure that the value is there for the education, which you will receive. Some employers offer a tuition benefit for employees that attend classes in an effort to better themselves. These companies see the value which an educated individual brings to the workplace and they are supportive of these efforts. Make sure that they will reimburse you for a class or a program before you enroll.

An important, yet often overlooked component of any education is a good, solid support mechanism. You need family and friends to be supportive, as there may be times when your classes need to take priority over another activity. This is also true of an online education and something that you should make sure is in place well before enrolling in your first class.

\section{CONCLUSION}

Before individuals decide to pursue classes, an online education is contingent upon many things. Some important factors to consider before ever taking the first online class should be the program design, knowing if the program is individual, team or a combination-based platform, understanding the differences and levels of commitments with a synchronous or asynchronous classroom, the cost to attend, and finally they should make sure that they have an adequate support system in place to reinforce the effort. It needs to be compatible with learning needs, priorities, budget and support.

\section{AUTHOR INFORMATION}

Allan Beck is actively employed by The University of Texas Pan American as a Field Engineer for the Rapid Response Manufacturing Center. He has served in many executive leadership roles prior to this appointment.

Having taught undergraduate and graduate business classes for two online universities, he has seen much in the evolution of online education as well as worked on several different platforms. He has taught for The University of Phoenix since 2001 and for Kaplan University since 2003. Mr. Beck is a doctoral candidate in Operational Leadership at The University of Phoenix.

\section{REFERENCES}

1. Bertera, E., \& Littlefield, M. (2003, August). Evaluation of Electronic Discussion Forums in Social Work Diversity Education: A Comparison of Anonymous and Identified Participation. Journal of Technology in Human Services, 21(4), 53-71. Retrieved February 28, 2009, from Academic Search Complete database.

2. Consider This When Choosing a Graduate Program. (2005, February 2). Critical Care Nurse, Retrieved February 28, 2009, from Academic Search complete database.

3. Miguel Gonzalez, PhD., Associate Dean, School of Engineering and Computer Science, The University of Texas Pan American. 956-381-2673.

4. Johnson, G. (2006, July). Synchronous and Asynchronous Text-Based CMC in Educational Contexts; A Review of Recent Research. TechTrends: Linking Research \& Practice to Improve Learning, 50(4), 46-53. Retrieved February 28, 2009, doi:10.1007/s11528-006-0046-9.

5. Jane Lemaster, PhD., Director of Online Education, The University of Texas Pan American. 956-292-7828.

6. John Lloyd, PhD., Director, Rapid Response Manufacturing Center, The University of Texas Pan American. 956-318-8955.

7. Merrill, H. (2003, Spring2003). Best Practices for Online Facilitation. Adult Learning, 14(2), 13-16. Retrieved February 28, 2009, from MasterFILE Premier database.

8. Roblyer, M., Freeman, J., Donaldson, M., \& Maddox, M. (2007, October). A comparison of outcomes of virtual school courses offered in synchronous and asynchronous formats. Internet \& Higher Education, 10(4), 261-268. Retrieved February 28, 2009, doi:10.1016/j.iheduc.2007.08.003.

9. Vess, D. (2005, October). Asynchronous Discussion and Communication Patterns in Online and Hybrid History Courses. Communication Education, 54(4), 355-364. Retrieved February 28, 2009, doi:10.1080/03634520500442210. 


\section{NOTES}

